14.8

\title{
Задачи разработки отечественных физических приборов для быстрой (без смены поколений) идентификации генотипов при отборах в расщепляющихся и диких популяциях растений
}

\author{
(C) В.А. Драгавцев
}

Агрофизический научно исследовательский институт, 195220 Санкт-Петербург, Россия

e-mail: dravial@mail.ru

Поступило в Редакцию 18 декабря 2019 г.

В окончательной редакции 18 декабря 2019 г.

Принято к публикации 17 февраля 2020 г.

В период 1984-2014 гг. наша научная школа (к 2018 г. - 35 кандидатов и 12 докторов наук) создала и развила новую Теорию эколого-генетической организации количественных признаков (ТЭГОКП). Теория базируется на открытии нового эпигенетического феномена - смены спектров продуктов генов под количественным признаком при смене лимитирующего фактора внешней среды. Из Теории вышли 24 приоритетных следствия и 10 ноу-хау, способных устранить „узкие места“ традиционных технологий селекции на повышение урожаев. ТЭГОКП породила экспериментально проверенные на многих сельскохозяйственных культурах 16 инновационных технологий конструирования прорывных сортов с.-х. растений с высокими урожаями и качеством продукции, в десятки и сотни раз более эффективные, чем традиционные селекционные технологии повышения урожаев. Первая из 16-и важная группа технологий быстрой (без смены поколений) идентификации самых продуктивных генотипов при отборах в расщепляющихся и диких популяциях описана в настоящей работе. Эта группа технологий основана на следствиях ТЭГОКП: принципе фоновых признаков и принципе „ортогональной“ идентификации максимальных плюсовых вкладов в урожай семи открытых генетико-физиологических систем (ГФС): аттракции; микрораспределений аттрагированных пластических веществ между зерном и мякиной в колосе; адаптивности (засухо-, жаро-, морозо-, холодо-, солеустойчивости и пр.); горизонтального иммунитета; „оплаты“ сухой биомассой растения низких доз почвенного питания $(\mathrm{N}, \mathrm{P}, \mathrm{K})$; толерантности к загущению фитоценоза; генетической вариабельности длин фаз онтогенеза.

Ключевые слова: теория эколого-генетической организации количественных признаков, принцип фоновых признаков, принцип „ортогональной“ идентификации семи ГФС.

DOI: $10.21883 / J T F .2020 .10 .49791 .413-19$

\author{
„Успех приложсения генетических знаний \\ $\kappa$ селекционному процессу определяется \\ разработкой экспресс-тестов в целях \\ увеличения скорости оценки генотипов \\ организмов по необходимым признакам \\ продуктивности“" \\ (Лобашев М.Е., Астауров Б.Л., Дубинин Н.П. \\ Современная генетика в решении задач \\ селекции. Журн. Генетика“, 1966, № 10, С. 22.)
}

В наши дни за сутки на Земле рождаются 250000 младенцев. К 2030 г. население Земли достигнет 8 млрд. человек. Если аграрии всех стран не смогут за это время увеличить объем растениеводческой продукции в мире в 2 раза, то над 2.5 млрд. людей нависнет угроза голодной смерти. Сегодня на Земле голодают 1.5 млрд. человек. Только за один 2011 г. в странах АТЭС число голодающих выросло на 40 млн. человек, а всего к 2012 г. достигло 200 млн. (из доклада В.В. Путина на САММИТЕ АТЭС-2012). По данным ФАО, за последние 50 лет совокупный объем мирового производства с.-х. продукции вырос в 2.5-3.0 раза, а площадь с.-х. территорий Земли - лишь на 12\%. Дальнейший рост с/х тер- риторий в мире - невозможен (Отчет ФАО за 2014 г., Рим). Сегодня в развитых странах агротехнологии почти доведены до возможного „потолка“. Дальнейшее повышение урожаев зерновых и зернобобовых в этих странах на 95\% зависит от улучшения селекционных технологий, и только на $5 \%$ - от улучшения агротехнологий.

Эксперты ФАО (в Отчете за 2014г.) подчеркнули: „Мировой опыт показал, что техногенная интенсификация растениеводства не способна решить проблему дальнейшего повышения урожаев, но при этом связана с ростом энергозатрат и нарушением экологического равновесия в природе. Глобальный кризис в с.-х. производстве XXI века требует новой стратегии - био- 
логизации растениеводства, т.е. создания устойчивых к абиотическим и биотическим факторам среды новых сортов, гибридов и видов с.-х. растений“.

В соответствии с этой общемировой ситуацией в РФ приняты важные документы:

1) в Решении Президиума Совета при президенте РФ по модернизации экономики и инновационному развитию РФ от 24.11.2014 подчеркнуто: „Необходимым условием инновационного развития растениеводства в РФ является использование новых сортов и гибридов с.-х. культур“;

2) в послании президента РФ Федеральному собранию от 08.12.2015 г. указано: „Совместно с РАН и при участии ФАНО обеспечить разработку . . . программы . . . по созданию отечественных посевного и племенного фондов“".

3) в Стратегии национальной безопасности РФ, утвержденной Указом президента РФ от 31.12.2015 г., пункт 54, с. 17 отмечено: „Продовольственная безопасность РФ осуществляется за счет . . . развития племенного дела, селекции и семеноводства.....

Эти документы полностью соответствуют утверждению: „Кто обладает продовольствием, тот имеет оружие сильнее атомной бомбы. В мире есть только две реальные силы - сила энергетических ресурсов и сила продовольствия“ (Эрль Батц, министр сельского хозяйства США в администрации президента Форда, 70-е годы ХХв.)

Эйфория от достижений генной инженерии растений начинает понемногу угасать. Многие страны сокращают площади под генно-модифицированными (ГМ) растениями. В 2016 г. Аргентина сократила посевы ГМ-растений на $3 \%$, Индия на $7 \%$, Китай на $24 \%$, Уругвай на $7 \%$. В Испании, Судане, Мексике, Колумбии, Вьетнаме, Португалии, Бангладеш, Коста-Рике, Словакии, Чехии площади ГМ-растений (в каждой стране) менее 100 тыс. ha и не обнаруживают приращения. Румыния в 2016 г. покинула клуб ГМО-стран. ГМ-картофель, устойчивый к колорадскому жуку, не выращивается сегодня нигде в мире. В большинстве стран Европы и в РФ посевы ГМ-растений запрещены.

Все более актуальной становится позиция Дж.Л. Брюбейкера: „Более половины населения нашей плодородной земли имеет слишком мало пищи, и даже очень глубокое знание гена дает небольшое утешение голодным людям, пока оно не выражается в калориях“ [1].

Появляются и более резкие оценки: „Генная инженерия - это единственная „инженерия“, которая не знает своих объектов и действует наобум. „Генный инженер“ подобен сварщику или резчику, лезущему с переделками в машину, устройство и назначение которой ему неизвестно“ [2].

Действительно, внедрение генной инженерии в растениеводство началось безо всякого понимания экологогенетического „устройства“ признаков продуктивности растений и при полном игнорировании экологогенетических механизмов феномена „взаимодействие генотип-среда“, только управление которым (бессознательное или сознательное) и определяет рост продуктивности и урожая новых сортов растений.

У современного трансгеноза очень много слабых мест.

Во-первых, он может работать только с одним „большим“ геном (олигогеном), затем с другим и т.д., но не может „пересаживать“ сложные полигенные системы, управляющие признаками продуктивности, да еще „блуждающие“ под признаком при сменах лимитирующих факторов среды.

Во-вторых, пересаженный ген может „сесть“ в любую хромосому и не только между генами, но и внутрь любого гена, что может привести к серьезным нарушениям генома - продукта длительной эволюции.

В-третьих, пересаженный ген не подчиняется „замку корреляций“ целостного организма (собственные гены индуцируются или „глохнут“ в зависимости от фазы развития, чужой ген работает всегда и везде, в любых органах и тканях организма, т.е. он ведет себя так же, как раковая клетка, не подчиняющаяся командам целостного организма).

В-четвертых, пересаженный ген не может поднять урожай, поскольку урожай формируется эффектами взаимодействия „генотип-среда“, а не отдельными генами.

В-пятых, „существующие методы трансформации растений малоэффективны, видо- и сортоспецифичны, приводят к случайному встраиванию чужеродной ДНК в геном реципиента, накладывают ограничения на количество переносимой информации и т.д. Переброс трансгенов из одного сорта в другой требует многократных возвратных скрещиваний и, главное, не является генетически чистой процедурой, поскольку вместе с чужеродной ДНК в процессе случайной рекомбинации происходит перенос различных „кусков“ ДНК сорта-донора.... Поскольку эффективной процедуры встраивания трансгенов в заранее заданный участок генома не существует, манипулирование даже несколькими независимыми признаками и их координированный переброс в сотни сортов превращаются в логистический кошмар для селекционных компаний“ [3].

5 мая 1966 г. Президиум АН СССР утвердил решение Секции химико-технологических и биологических наук по докладу члена-корреспондента АН СССР Н.П. Дубинина „Практические задачи генетики в сельском хозяйстве“. В решении сказано: „Первоочередными проблемами в области генетики растений... являются следующие: а) генетические основы гетерозиса и методы получения высокоурожайных гетерозисных гибридов с.х. растений, в первую очередь у пшеницы, кукурузы, овощных и технических культур; б) закономерности наследования количественных признаков, определяющих продуктивность с.-х. растений...; в) дальнейшее совершенствование методов отбора в селекции с.-х. растений“. И далее: „Поручить дальнейшую разработку научных основ новых методов генетической селекции - ИОГен АН СССР, ИЦиГ СО АН СССР, Ин-ту хим. физики АН СССР, Ин-ту генетики и цитологии 
АН БССР, Ин-ту микробиологии АН СССР, Ин-ту цитологии АН СССР“ („Генетика“ № 8, 1966, С. 186-188).

Однако из всех НИИ только группой сибирских генетиков (ИЦиГ СО АН) и селекционеров восьми сибирских НИИСХ в процессе выполнения Кооперированной межведомственной программы ДИАС (Генетика признаков продуктивности сортов яровой пшеницы в Западной Сибири - на территории от Урала до Забайкалья и от Тюмени до Усть-Каменогорска, 1974-1984) [4] была открыта новая система регуляции развития свойств продуктивности - смена спектров продуктов генов, детерминирующих один и тот же признак, при смене лимитирующего фактора внешней среды.

На основе этого открытия в период 1984-2014 гг. научной школой $\quad$ В.А. Драгавцева (к 2018 г. 35 кандидатов и 12 докторов наук) была развита приоритетная Теория эколого-генетической организации количественных признаков (ТЭГОКП) с 24-мя оригинальными научными следствиями и 10-ю селекционно-мощными ноу-хау [5,6]. Теория и ее элементы включены в Международную энциклопедию „Basic Life Sciences“ [7], в Толковый словарь по общей и молекулярной биологии, общей и прикладной генетике, селекции, ДНК-технологии и биоинформатике [8], в Толковый словарь по инновационным вопросам селекции, семеноводства и размножения растений [9], в Краткий словарь терминов по лесной генетике (принцип фоновых признаков) [10].

\section{Как была решена проблема$$
\text { № } 1 \text { - необходимость создания }
$$$$
\text { методов надежной идентификации }
$$$$
\text { лучших генотипов по продуктивности }
$$$$
\text { при индивидуальных отборах }
$$$$
\text { в расщепляющихся гибридных }
$$$$
\text { поколениях, начиная } \mathrm{c}_{2}
$$$$
\text { (или в диких популяциях) }
$$

До ТЭГОКП принципиальная возможность быстрой (без смены поколений) идентификации (узнавания) генетически лучших растений по их фенотипам в расщепляющихся генерациях категорически отрицалась следующими утверждениями.

Профессор Н.П. Кренке [11] отмечал: „Начиная от первых стадий развития не существует константно особого феногенетического выражения для модификаций и наследственных признаков“.

Профессор Н.А. Плохинский [12] подчеркивал: „Для одной особи бессмысленно определять, какая часть ее фенотипа обусловлена наследственностью, а какая условиями жизни. Генетическая информация, полученная одним индивидуумом, реализуется в таком взаимодействии с условиями жизни, при котором обе причины неотделимы друг от друга,,
Профессор У. Уильямс [13] утверждал: „В продуктивности одного организма невозможно разделить генетические и внешние воздействия на признаки со слабой наследуемостью, и отбор в $\mathrm{F}_{2}$ ненадежен“.

Заведующий лабораторией крупного рогатого скота ИЦиГ СО АН 3.С. Никоро и соавторы [14] сожалели: „Для оценки генотипа необходимо знать величину генотипического значения признака, однако нет способа отделить генотипическое значение от экологического для каждой отдельной особи“".

Академик П.Ф. Рокицкий [15] писал: „Фенотип особей - это единый целостный организм. О генотипе особей непосредственно, без анализа их потомства, судить невозможно,

Профессор В.К. Савченко [16] считал: „Вычленить непосредственно для каждого организма влияние на развитие признака генотипа и среды - не представляется возможным“.

Экспериментальная оценка эффективности традиционных визуальных отборов по фенотипам показала, что из 1000 отобранных растений с лучшими фенотипами (при отборах на фоне легкой засухи) генетически ценным оказалось лишь одно растение, т.е. точность „узнавания“ генотипа по его фенотипу составила около 0.001 [17]. В таких ситуациях случайный отбор теоретически может быть эффективнее отбора по лучшим фенотипам. Создается впечатление, что постулаты шестерых крупнейших феногенетиков и генетиков справедливы.

Однако первое следствие ТЭГОКП - принцип фоновых признаков (ПФП) - теоретически и экспериментально отверг эти утверждения $[18,19]$ и создал методы быстрой (без смены поколений) идентификации генотипического значения любого признака продуктивности у отдельной особи в расщепляющейся популяции с точностью, до 1000 раз превышающей точность традиционного визуального „узнавания“ генетически ценной особи [20].

Дальнейшее развитие ПФП и открытие семи генетикофизиологических систем, де-факто повышающих урожаи новых сортов (1 - аттракции, 2 - микрораспределений пластических веществ между зернами и мякиной, 3 - адаптивности к разным лимитирующим факторам внешней среды, 4 - горизонтального иммунитета, 5 „оплаты“ сухой биомассой лимитирующего фактора почвенного питания $(\mathrm{N}, \mathrm{P}, \mathrm{K}), 6$ - толерантности к загущению агрофитоценоза, 7 - генетической вариабельности длин фаз онтогенеза) породили принцип разнонаправленной („ортогональной“) идентификации (ПРИ) [21], что позволило, во-первых, быстро (без смены поколений) идентифицировать плюсовые генетические вклады каждой из семи генетико-физиологических систем (ГФС) в продуктивность любой особи, во-вторых, отказаться от традиционных низкоэффективных визуальных отборов по фенотипическим значениям признаков (что делали и делают все селекционеры мира уже в течение многих сотен лет), и, в третьих, использовать 
величины признаков продуктивности в качестве специальных двумерных координат, в которых все „шумы“ (экологический, конкурентный генотипический и конкурентный экологический) сдвигают точку сорта по положительной линии регрессии, а ценный плюсовой сдвиг ГФС, например аттракции, - по отрицательной (эффект „ортогональности“). При этом ценный вклад в урожай любой ГФС „очищается“ от маскирующих эффектов всех шумов и проявляется (и измеряется) с абсолютной точностью.

Из ТЭГОКП [5] вышла гипотеза о необходимости существования у растений так называемых „фоновых признаков“ (ФП), которые нечувствительны к мутациям и рекомбинациям, сдвигающим экономически важные признаки продуктивности, но очень чувствительны к колебаниям средовых факторов, лимитирующих рост, развитие и продуктивность растений. Если ФП удастся экспериментально обнаружить, то в принципе можно будет заменить традиционный трудоемкий и длительный метод идентификации генотипа по его потомству („корреляция родитель-потомок“ - ему более 300 лет) на быстрый метод - без смены поколений.

Многолетние поиски ФП обнаружили ФП разной природы:

1) ФП возникают как продукты локусов, не имеющих генетического полиморфизма в популяции, но чувствительные к колебаниям уровня лим-фактора среды.

2) ФП могут быть признаки-датчики, регистрирующие и передающие организму информацию о напряженности лим-фактора среды. Такие признаки не могут иметь генетического разнообразия в популяции (это приведет к искажению информации, поступающей от среды к организму, поэтому они эволюционно обязаны быть ФП).

3) ФП могут быть результатом универсальности для растений общих координирующих систем онтогенеза (гормоны, фитохром и т. п.) эволюционирующих гораздо медленнее морфологических признаков продуктивности.

4) ФП могут возникать из не фоновых при определенных дозах субстрата во внешней среде, если они формируются субстрат-индуцибельными ферментами (малое количество субстрата приведет к полной выравненности активности фермента у всех особей популяции, тогда как на фоне обильного субстрата проявится сильная генетическая вариабельность активности фермента).

5) Все количественные признаки с аддитивным генетическим разнообразием, имеющие адаптивное значение, в процессе отбора „выходят на потолок“ и превращаются в ФП с нулевой генетической вариансой.

6) Все высоко полигенные признаки обладают высокой буферностью к мутациям и рекомбинациям. Как правило, все они хорошие ФП.

Удалось установить, что универсальными ФП для всех растений являются ФП 6-ой группы. Из них лучшие:

А) осмотическое давление в клетках надземных органов. Для его регистрации нужны портативные рефрактометры, способные очень быстро замерять рефрактометрический индекс клеточного сока. Нужны портативные прессы с большим давлением для отжимания клеточного сока из тканей с большим процентом связанной воды.

Б) оводненность тканей листьев (хвои), стеблей, элементов ствола (камбия, живой коры, древесины). Для быстрой регистрации сравнительной оводненности нужны портативные приборы измерения импеданса с большим разнообразием переменных токов, разнообразием щупов с разными размерами игл на щупах и с изменяющимися расстояниями между иглами.

В) оводенность внутренних тканей (стеблей, стволов). Для ее регистрации нужны портативные тепловизоры с разнообразным набором объективов и широкой регуляцией чувствительности.

Г) нужны компактные рентгеновские установки для оценки глубины заложения узла кущения у хлебных злаков, оценки числа зерен в колосе в фазу колошения, оценки повреждений зародышей в семенах, оценки выполненности стеблей злаков, оценки качества срастания привоя и подвоя (плодовые и виноград). Эти приборы должны базироваться на новом принципе рентгенографии, открытом президентом РАЕН (СПб) акад. Г.Н. Фурсеем.

Д) нужны „очки селекционера“, созданные на основе оптической физики, позволяющие видеть уровень содержания в живых плодах растений ценных соединений (например, ликопина в томатах и т.п.)

Эксперименты показали, что, например, импедансная идентификация отдельного генотипа в расщепляющейся (или дикой) популяции производится за $0.5 \mathrm{~min}$, тогда как по традиционной „корреляции родитель-потомок“ для однолетних растений нужен минимум 1 год, а для древесных - требуется минимум 10-15 лет.

\section{Благодарности}

Выражаю благодарность Агрофизическому институту, Экологической комиссии ЗАКС Ленинградской области, Группе компаний „МИР“ за поддержку этой работы.

\section{Финансирование работы}

Работа была финансирована грантами Российского фонда фундаментальных исследований: № 07-04-01714; № 13-01-96519; № 16-04-00199.

\section{Конфликт интересов}

Автор заявляет, что у него нет конфликта интересов.

\section{Список литературы}

[1] Брюбейкер Дж.Л. Сельскохозяйственная генетика. М.: Колос, 1966. 223 с

[2] Иванов Ю.Н. Мысли о науке и жизни. 4-е изд. Новосибирск: Свиньин и сыновья, 2011. 398 с.

[3] Лутова Л.А. Современные технологии в биологии растений. Материалы всероссийской школы молодых ученых по экологической генетике. Краснодар, 2012. С. 82-100. 
[4] Драгавцев В.А., Цильке Р.А., Рейтер Б.Г., Воробьев В.А., Дубровская А.Г., Коробейников Н.И., Новохатин В.В., Максименко В.П., Бабакишиев А.Г., Илющенко В.Г., Калашник Н.А., Зуйков Ю.П., Федотов А.М. Генетика признаков продуктивности яровых пшениц в Западной Сибири. Новосибирск: Наука, 1984. 230 с.

[5] Драгавщев В.А., Литун П.П., Шкель Н.М., Нечипоренко Н.Н. // ДАН СССР. 1984. Т. 274. № 3. С. 720-723.

[6] Драгавцев В.А. // Биосфера. 2012. Т. 4. № 3. С. 251-262.

[7] Межсдународная энциклопедия „Basic Life Sciences“. NY., London: Plenum Press. Vol. 8. P. 233-240.

[8] Глазко В.И., Глазко Г.В. Толковый словарь по общей и молекулярной биологии, общей и прикладной генетике, селекции, ДНК-технологиям и биоинформатике. Т. 2. М.: Академкнига, Медкнига, 2008. 530 с.

[9] Макрушин Н.М., Драгавцев В.А., Плугатарь Ю.В., Малечкий С.И., Малько А.М., Макрушина Е.М., Шабанов Р.Ю. Толковый словарь по инновационным вопросам селекции, семеноводства и размножения растений (русско-английский). Симферополь: Диайпи, 2017. 207 с.

[10] Краткий словарь по лесной генетике. (Принцип фоновых признаков В.А. Драгавцева). Красноярск: Наука, 2015.

[11] Кренке Н.П. Феногенетичесчкая изменчивость. Т. 1. М.: Биологический ин-т им. К.А. Тимирязева, 1933-1935. $860 \mathrm{c}$.

[12] Плохинский Н.A. Наследуемость. Новосибирск: Наука, 1964. $196 \mathrm{c}$.

[13] Уильямс У. Генетические основы и селекция растений. М.: Колос, 1968. 448 с.

[14] Никоро 3.С., Харитонова 3.Н., Решетникова Н.Ф. Различные способы определения племенной ценности животных. М.: Колос, 1968. 446 с.

[15] Рокицкий П.Ф. Введение в статистическую генетику. Минск: Вышэйшая школа, 1974. 448 с.

[16] Савченко B.К. Генетический анализ в сетевых пробных скрещиваниях. Минск: Наука и техника, 1984. 223 с.

[17] Литун П.П. Разрешающая способность современных схем селекционных отборов. Материалы 4-го Всесоюзного съезда ВОГиС им. Н.И. Вавилова. Кишинев, 1982. Т. 2. Генетика растений. С. 89-91.

[18] Драгавцев В.А., Острикова В.М. Поиск фоновых признаков для экспрессной оценки генетической изменчивости в растительных популяциях. Генетика. 1972. № 8 (4). C. 33-37.

[19] Драгавцев В.А., Погожсев И.Б., Соколова Т.А. Количественные оценки генотипических значений признаков растений с учетом распределения экологических отклонений у фенотипов. Модели экосистем и методы определения их параметров. Новосибирск: Вычислительный центр CO AH, 1981. С. 190-196.

[20] Драгавцев В.А. Генетика количественных признаков растений в решении селекционных задач: Диссертация дра биол. наук: 03.00.15 (генетика). Институт общей генетики АН СССР. М., 1984.

[21] Дьяков А.Ю., Драгавцев В.А. Разнонаправленность сдвигов количественного признака индивидуального организма под влиянием генетических и средовых причин в двумерных системах признаковых координат. Экологогенетический скрининг генофонда и методы конструирования сортов с.-Х. растений по урожайности, устойчивости и качеству. СПб.: ВИР, 1998. С. 23-40. 